\title{
Industrial Projects in a Project-Based Learning Environment
}

\author{
Calin Stoicoiu and Karen Cain \\ Conestoga College Institute of Technology and Advanced Learning \\ Cstoicoiu@conestogac.on.ca, Kcain@conestogac.on.ca
}

\begin{abstract}
Industry is progressively moving at a faster pace with complicated problems and projects that require increasingly rapid turn-around. Newly graduated engineers are often required to work on projects having, in many cases, poorly defined scope, constraints and outcomes. In addition to their technical knowledge, employers expect enhanced communication, entrepreneurial and managerial skills.

Project-based learning (PBL) enhances engineering education, providing students with a setting that closely simulates their post-graduation work environment. The addition of projects into the engineering curriculum creates avenues towards improving communication, individual growth, life-long learning and team-work; skills that industry desires. The key has always been to present students with problems and projects that are as open-ended and realistic as possible, creating situations that closely resemble those encountered in industrial settings, such as: project requirements that are not well structured, changes to project scope and timelines and the need to address a customer's changing needs or expectations.

The addition of a real project in cooperation with an industry partner may be the ultimate method of achieving these goals. The development and management of the project is complex involving students, faculty, and the industry partner, but generates tangible advantages for all three parties. This paper will discuss the many benefits and challenges of incorporating a real industrial project into the educational environment.
\end{abstract}

Keywords: Project-Based Learning, Engineering Education, Industry Partner, Project, Benefits, Aptitudes

\section{INTRODUCTION}

Project-based learning (PBL) is an established teaching philosophy that combines theory and practical application though the use of projects embedded in the curriculum. It is an active form of learning where students "learn by doing" [1]. It develops big picture thinkers with the hard and soft skills that engineers need to be successful in industry [2-6]. Industry wants graduate engineers with the following qualities: ability to work in a group, superior critical thinking skills, ability to deal with ill-defined and complex problems, and an entrepreneurial attitude [7]. Project-based learning is well situated to provide students with these skills.

Models for PBL exist within a continuum, ranging from a single capstone project at the end of a program to projects linking learning outcomes within a course, a semester or a year; to a curriculum consisting entirely of projects where all learning, both theoretical and practical, occurs within the framework of the projects [8]. The undergraduate program outlined in this paper, Conestoga's Mechanical Systems Engineering (MSE), uses a hybrid PBL model where traditional courses and a project course are delivered side-by-side in each year, integrating theoretical learning with practical applications and allowing students to integrate ideas across engineering disciplines. Often, certain course topics are delivered in a just-in-time method to facilitate project deliverables. Other times, project activities reveal new concepts, not covered in class. This results in graduate engineers who are big picture thinkers and practically minded.

PBL has a way of mimicking the real world of a graduate engineer, with students working in diverse groups to solve a problem e.g. building a machine. Projects can be either 'build' projects where the machine is designed and then physically manufactured or paperbased with the design aspect only. Modelling and/or virtual simulations are also possible. Build projects lead to increased technical skills and allow for trouble-shooting of the final product, but they have the downside of requiring more time and additional funding.

The best type of project is one that is open-ended and closely resembles real life, using many project constraints and the need to satisfy customer needs and wants in a timely and economically-conscious fashion [9]. Many academic projects are well-structured and take place in a 'sterile' academic environment. These projects, although still better than no project at all, are much too simplified to fully form the skills that students will require in an industrial setting. These projects do not have everchanging needs and goals, nor do they have varying obstacles [7]. One solution is to include an industrial project within the curriculum. An industrial project can fill all of these roles and has the advantage of being winwin-win. The students, the faculty, and the industry all benefit. Of course this does not mean this type of project is easy, either in its implementation or in its delivery. There are challenges that go along with the many benefits. 
This paper will introduce the MSE third year industrial project; the set up process, the day-to-day management and evaluation methods. It will also bring to light the benefits and challenges to the three main stakeholders: the students, the faculty member and the industry partner.

\section{PROJECT-BASED LEARNING IN MSE}

In the MSE third year project, up to 20 students work organized in groups of four or five to design and build a prototype or proof of concept for various automated manufacturing and / or assembly applications. Each group is responsible for the design and build of a sub-system or component of the final project solution. Students will need to work closely with the industrial company to assess their needs and define the project constraints. They will have to communicate effectively with external suppliers, as manufacturing will usually be outsourced. Students must also effectively manage their project group with formal delineation of duties and responsibilities.

The project covers two academic terms and includes:

\section{Semester 1 - Phase A Design (4 months)}

Project description and constraints

Preliminary design ideas presented to the industry customer

Finalization of design solution

Mechanical analysis studies for design validation

Assembly and detail drawings, material flow plans, sourcing of components

\section{Semester 2 - Phase B Build and Present (4 months)}

Outsourcing of machined components and project build

Design of system controls

Troubleshooting

Final demonstration

\section{Completing project documentation}

The previous steps are taken by the students and are shown in Fig. 1 as steps 7 to 12 . Of course, there is much work to be done before a project arrives at the stage where it is ready to be presented to students. The preparation for an industrial project requires the project coordinator to source industry partners with unique projects and to work with them to establish a project description and scope. This is outlined in Fig. 1, steps 1 to 6 .

\section{PROCESS SETUP AND DEPLOYMENT}

\subsection{Preliminary setup activities}

Industrial project opportunities exist in abundance as various real-life problems in need of solutions. Small and medium size companies seldom have the necessary resources to perform the research and development work required to solve these problems. Engineering programs designed around the project-based learning principles can offer valuable solutions to many of these challenges.
Many companies have realised that a team of students can do a great job trying to find a good solution to one of their problems even though the goal for the students is to learn and the problem is just a tool [7].

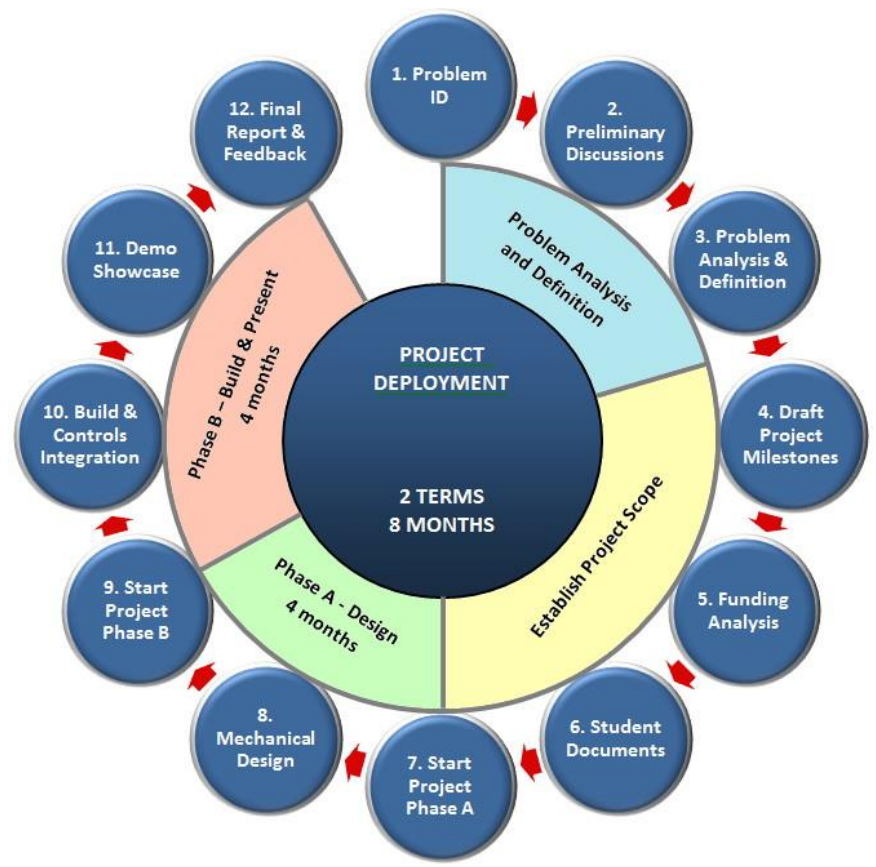

Fig. 1. Project deployment

3.1.1 Problem analysis and definition. The very first step is the identification of the industry originated problem that later becomes the project scope. Either the industry partner or the education institution can initiate this first contact through networking and using contacts shared among program faculty members.

One or more meetings involving the two parties follow, creating the initial link between the problem specifics (complexity and expected deliverables) and the particular constraints of the current student cohort (number of students), faculty and the institution/program resources availability. An important parameter is the time constraint associated with both the industry partner's needs and the rather rigid academic semester the project occupies in the program. Often, the needed solution is required faster than academia can deliver it. Traditionally the ideal match results when the company can afford to wait, usually from eight months to a year. This translates into the possibility to setup the project over two academic terms. Particularly for MSE, the third year project runs over the winter and summer terms, for a total of eight months. This timing has proved to be generally sufficient to obtain the desired project results.

The most important step of the preliminary setup process involves the translation of the real-life problem, as presented by the industry partner, into a properly defined problem, in engineering terms. Real-life problems are not defined in engineering terms. Therefore, problem analysis, 
definition and formulation in engineering terms are very important, before starting with the problem solving [7]. Often, partners from industry specify their desired outcome, generally without the knowledge of its implications or the implementation complexity and other various constraints. A thorough analysis is performed using, when applicable, optimization tools as Quality Function Deployment and House of Quality. The goal is to establish concrete engineering solutions to the industry partner's needs as projected by the identified problem.

3.1.2 Establishing the Project Scope. The properly defined engineering problem that accurately encompasses industry partners' needs and criteria provides clear direction for organizing the project in discrete milestones and their deliverables. The MSE third year project is organized in the program curriculum as two courses, occupying two consecutive terms. In order to properly integrate these courses with the supporting curriculum, a generic sequence of high-level milestones was developed to fit most of the industry generated project themes. However, after the specific problem is defined, with each project occurrence these milestones and deliverables are re-visited and customized accordingly. For example, certain projects can have a heavy mechanical design component while others, a complex automation control setup. At this point, project funding decisions are made; preliminary cost estimation is generated and based on the cost magnitude certain funding channels are explored. Traditionally, the MSE third year project funding is supported by:

1. The MSE program budget allocated for this project

2. Various government funding programmes from agencies as NSERC, FedDev, OCE, CONNI, etc.

3. Industry partner's in-kind and cash contributions

Funding sources are identified prior to the project's start and actual arrangements are secured prior to or during the first two months of Phase A (see Fig. 1).

The project preparation phase concludes with the generation of project description document presented to the students at the beginning of Phase A in January.

\subsection{Project Phase A - Design}

As part of the first phase of the project deployment to students (see Fig. 1), students receive the project description document and organize themselves into groups of 4 or 5. The first four weeks are dedicated to research of the specific problem and constraints, followed by preparation of preliminary high-level conceptual designs for the envisioned solution. A unique element is that each group of students will work independently to produce an original solution regardless of which sub-group they may eventually be a member of. This model expands the quality of the generated ideas through competition. At the end of the first month each group presents their preliminary design to a panel including, the industry partner, faculty project coordinator and other program faculty. Written proposals are also prepared and evaluated. Once these concept proposals are presented and defended, feedback is given, and a unique preliminary design and set of directions are established.

A re-distribution of resources takes place, new student teams are formed, each responsible for newly identified, specific tasks. Student groups can be selected by the coordinator or by the students themselves. Based on the MSE experience, the self-selection process has always worked better. By third year, students have had many opportunities to work in teams on PBL projects, and as a result, self-selected teams have been very successful. Third year students recognize the benefits of diversity of knowledge and skills sets and will most often select teammates that have complementary talents. Interventions by the coordinator to correct group dysfunctions are seldom needed. Self-selection also transfers some of the responsibility team management to the students [9].

Phase A continues with the mechanical design and required analysis of the identified project solution. During the contact time with the students, the faculty coordinator provides guidance and oversees the process. Individual log books are kept and revised by the students and weekly progress notes are recorded for the individual performance evaluation. Concluding this first phase, a first iteration of manufacturing drawings is prepared including a complete Bill of Materials for purchased and custom manufactured components.

\subsection{Project Phase B - Build and Demonstrate}

The first priority of this second term is editing and feedback of mechanical drawings. This documentation is used for manufacturing custom mechanical components outsourced to third party suppliers, with students being responsible for communication and follow up with these suppliers. Typical purchasing documentation is generated following the College's practices. Custom designed components are usually not cost-recoverable and are usually considered a yearly program expense. Industrial partners help cover these costs through cash or in-kind contributions and often partnering companies will retrieve the equipment they invested in for after the project build.

A preliminary report is now generated by the students, containing the automation controls design with a complete list of automation controls components and parameters. At this point, students form new groups, for the electrical and automation controls systems design.

While custom mechanical components are purchased and manufactured, another group of students create the assembly documentation for the entire project. In addition, students also develop a project management document based on the activities from previous term and projections 
of remaining tasks and milestones. This document must be updated on an ongoing basis.

The integration of mechanical, electrical and adjacent systems is now undertaken, bringing the entire group together, involving the participation of all. It is important to note that task-specific student leaders almost always surface, playing an active role in the project advancement. Leadership tasks throughout the entire project are often rotated with students alternately sharing leading and following roles, based on their own skills and abilities.

Testing and troubleshooting operations are performed next, representing excellent active learning activities. Students may learn just as much, or more, from making mistakes as from getting it right [9].

After all the encountered problems are resolved to the teams' best abilities, the final project step is preparation of the final report. It is important to note that this is not a gargantuan task left to the end of the project, as students have the opportunity to produce, collect and organize most of the final report content throughout project deployment. Rather, this task focuses on organizing and completing the documentation. A final report section on lessons learned and suggestions for improvement, exercises the students' critical thinking abilities and allows for reflective practice. Students proudly demonstrate their hard work during a project showcase attended by members of industry and the public. Merit awards are also acknowledged at this event.

It is very important to note that many project activities are supported by courses previously completed or concurrently attended by the students. They use acquired knowledge on technical communications, mechanical design, automation controls and financial / project management to complete various project tasks. Conversely, students use the project deliverables and activities as subjects of discussion in other courses within the curriculum. Students are also expected to perform significant self-learning and research tasks under the guidance of the project coordinator and faculty group.

\section{BENEFITS AND CHALLENGES OF INDUSTRIAL PROJECTS ACTIVITIES}

Before the distinct benefits and challenges industrial projects are addressed, it is obvious that real-life problems, as well as real industrial projects, are a much more effective catalyst for active learning compared with well planned, simulated and carefully polished project themes designed by faculty. Controlled and highly integrated academic projects are quite beneficial during the early, fundamental years of study. Although these "designed in house" projects are carefully integrated with the supporting curriculum by applying appropriate topics and outcomes, they lack the motivating factors, authenticity and energizing challenges associated with genuine problems originating from industry. As students do not wish to end up with a bad solution, they work very hard on their project [7]. The knowledge that they gain working on a real problem brought in by industry, creates a very strong motivating agent. During the third year of study in the MSE program, industrial projects are an excellent opportunity for students to master solid problem-solving capabilities.

The following is one student's remark:

"For RIM to come to us and tell us what they wanted, and for us to go ahead and design it and actually manufacture it and see it work now, is quite amazing”.

What could better illustrate the satisfaction and sense of achievement of a group of students during the successful demonstration of their eight months of hard work?

This leads very well into discussing the benefits of industrial projects for students:

1. Exposure to the additional learning opportunities generated by design corrections throughout the build phase. This represents a core value of PBL.

2. Development of superior analytical ability. Students must research problems and identify solutions that need assessment and often testing/simulation. Opportunities exist for reflection, discussion and interpretation of numerous and varied topics from an engineering perspective.

3. Growth of teamwork skills. Students are organized in medium size groups and must develop appropriate project management and group dynamic skills.

4. Improvement of presentation skills. There are many opportunities to present concepts and ideas, including defending project proposals in front of the industry partner.

5. Exposure to collaboration and communication with third party suppliers and the accompanying project planning and scheduling tasks.

6. Expansion of knowledge through brainstorming meetings and improvement of communication skills.

7. Exposure to financial management tasks, such as budget control.

8. The accolades of industry as shown through industrially sponsored awards for best project performance.

9. Tangible experience that students may record in their résumés.

10. Networking opportunities and possible new contacts for future jobs within the industry.

Faculty also benefit from coordinating and participating as advisors in an industry based project in the following ways: 
1. Remain current with the latest industry trends in their fields of expertise.

2. Exposure to domains within and outside of their main area of expertise, for continuous learning and expansion of abilities.

3. Opportunity to practice and master management skills and develop enhanced leadership qualities.

4. Expansion of their professional network.

5. Creates many possibilities to engage in and expand scholarly activities.

6. Excellent applied research opportunities.

The industry stakeholder experiences tangible benefits from having some of their current problems or concerns solved by academia. The MSE third year project always produces as final deliverable some form of prototype or proof of concept. Even if this result will not solve all problems, it will provide answers to many uncertainties. In summary, through these kinds of projects the industrial partner will:

1. Outsource the research and development activity.

2. Keep the prototype or proof of concept for further testing and experimentation.

3. Obtain valuable results and information from the final documentation accompanying the project.

4. Have access to un-biased "out-of-the-box" thinking models, differing from the company's established patterns.

5. Have the opportunity to engage in a dynamic dialogue with faculty and students that usually ends up revealing unexpected new ideas or outcomes, not anticipated at the beginning or planning stages of the project.

We have seen how projects involving industrial partners clearly bring numerous clear advantages to all three parties involved: students, faculty and the industry partner. There is, however, one other side of the coin: industrial projects contain additional level of complexity to the already challenging PBL environment. There is no shortage of obstacles and difficult tasks throughout the project setup and deployment. Open-ended group projects can be less useful for developing and reinforcing some of the individual skills [9]. Students are simultaneously engaged in traditional learning within other courses in their engineering program and the additional strain of a project such as this can be particularly demanding and requires a lot of determination and passionate, hard work. Faculty and supporting staff must fully commit to these projects' objectives and closely monitor students' activities. It is a key requirement to maintain an open and continuous communication with students and the industry partner. The project coordinators' role becomes critical, as this position demands considerable additional time and effort.

Some of the demonstrated challenges of industrial projects in the academic environment are:
1. Industry partner's expectations can go beyond the practical educational environment capabilities. A careful and true analysis of the project scope is critical to avoid this.

2. Project funding difficulties. Often small companies cannot participate financially towards the project and other funding opportunities might not be readily available.

3. Problem definition difficulties; lack of clarity form the industry partner's side regarding the desired outcome or true need. Long negotiations and false expectations can easily surface.

4. Cooperation difficulties with third party suppliers. These projects require extensive collaboration with many third party entities. Usually the educational institution has limited support staff resources to facilitate these interactions.

5. The project time frame lacks flexibility due to the specific academic terms starting and ending dates.

6. When the project involves the execution of a prototype, the acquisition of equipment and components often must take place in a just-intime manner. Design iterations and changes can occur at anytime, requiring immediate reaction and support.

7. The industry partner can modify the project scope or change the expected deliverables, demanding immediate executive decisions that must maintain the project's academic value and practical relevance.

In addition to these generic shortcomings, there are also obstacles originating from specific project setup or deployment phases:

As mentioned, Phase A starts with the generation of the initial concepts as proposed by each of the student groups. One challenge is to ensure that each group will have their most valuable contribution captured in the final solution. Each group of students will defend their ideas and sometimes industry partner's feedback is not accepted. At times several hours of discussions and brainstorming are required to reach this final decision. This experience alone enhances students' ability to provide and accept constructive criticism. It is the role of the project coordinator to moderate discussions and to facilitate the implementation of mutually acceptable outcomes. This is not an easy task.

Evaluation of students' individual and group work represents another challenge. Group work evaluation is simpler to perform as the main project deliverables are produced in this fashion. Individual student participation, on the other hand, relies on several parameters:

1. Records in student's personal project logbook.

2. Group peer and self-evaluation data (each team member evaluates the others and themselves). 
3. Project coordinator's notes of each group member's participation

Based on the MSE experience, it is very helpful to develop detailed marking rubrics, having specific criteria with carefully chosen weightings in order to assess each major milestone or deliverable.

During the building Phase B portion of the project, students engage in tasks based on individual skills and abilities and evaluations based on a structured approach can no longer be used. Creative evaluation methods must be developed such as the one used in MSE, which includes the allocation of 'points' proportional with students' ability and participation levels in tasks and milestones they were involved in. There is a tendency for the group to specialize within the task and the person who is most skilled, or most willing, is likely to do the majority of work [9].

In addition, the industrial project will often reveal concrete, direct applications of various theoretical topics learned in other classes. These opportunities have a major impact on students' experience, providing the best link between learned abstract concepts and their practical, real use. This represents active learning in its purest form.

\section{CONCLUSIONS}

Engineering degree programs are incontestably enriched by project-based learning models. Living proof exists through numerous examples of students having enhanced their readiness and preparation for professional life. Learning by applying and actively experiencing is more effective by engaging students from the early stages of engineering education and connecting them to the realities of their future profession. Industrial projects create and enhance this connection, exposing faculty, students and the industry partner to all of the many challenges and rewards of this sometimes difficult but ultimately satisfying PBL process of solving real problems by ingenuity and determination.

\section{Acknowledgements}

We would like to acknowledge the students for their dedication and hard work together with all participating industry partners, our colleagues, administration and all departments at Conestoga College, for their support and contributions.

\section{References}

[1] Charles L. Outcalt, Shannon K. Faris and Kathleen N. McMahon, Developing non-hierarchical leadership on campus: Case studies \& best practices in higher education. Westport, CT: Greenwood Publishing, 2000. . \{ISBN: 9780313-31178-9\}

CEEA14; Paper 65

Canmore, AB; June 8-11, 2014
[2] Sanjeev Kumar, "Industry preparation in a capstone design course," in Proc. International Conference on Engineering Education, International Network for Engineering Education and Research, (Taiwan, August 13-18, 2000).

[3] Debbie Lam, "Problem-based learning: An integration of theory and field," Journal of Social Work Education, vol. 40, no. 3, pp. 371-388, 2004.

[4] Sanjeev Kumar and J. Kent Hsaio, "Engineers Learn "Soft Skills the Hard Way": Planting a seed of leadership in engineering classes," Leadership and Management in Engineering, pp. 18-23, January 2007

[5] Sandra Cocco, Student Leadership Development: The Contribution of project-based learning. Diss. Master's thesis, Royal Roads University (Canada), 2006.

[6] Russell C. Walters and Todd Sirotiak, "Assessing the effect of project based learning on leadership abilities and communication skills," in Proc. $47^{\text {th }}$ ASC Annual International Conference, Associated Schools of Construction, (Omaha, NE, April 6-9, 2011).

[7] Flemming K. Fink, "Problem-based learning in engineering education: a catalyst for regional industrial development" World Transactions on Engineering and Technology Education, vol. 1, no. 1, pp. 29-32, 2002.

[8] Karen Cain and Sandra Cocco, "Leadership development through project based learning," in Proc.2013 Canadian Engineering Education Association Conference, CEEA, (Montreal, QC, June 17-20, 2013).

[9] Mats Daniels, Xristine Faulkner and Ian Newman, “Openended group projects, motivating students and preparing them for the 'real world'," in Proc.of the $15^{\text {th }}$ Conference on Software Engineering Education and Training, CSEET'02, (Covington, KY, February 25-27, 2002). 